\title{
Evaluation of a 5-Year Forecast
}

\author{
Joseph Vederman \\ 350 Beirut Avenue, Pacific Palisades, Calif. 90272
}

\begin{abstract}
A forecast 5 years in advance for each of 6 successive days is verified. Although the forecast has some interesting features, forecasters did not rate it highly. The forecast correlates lower with verifying observations than a monthly normal forecast does.
\end{abstract}

\section{Introduction}

Accurate weather forecasts for seasons, years, and decades in advance have been a dream of mankind for many thousands of years.

The present status of long-range forecasts has been summarized by the American Meteorological Society (1976, p. 1460, p. 1461):

For periods of more than 1 month: skill in day-to-day forecasts is nonexistent and skill in seasonal outlooks and climate forecasts is minimal at the present time. . . .

Recent theoretical work on atmospheric predictability indicates . . . an upper limit for the prediction of dayto-day weather changes. This limit is believed to be about 1-2 weeks. ...

At present the National Weather Service issues experimental long-range forecasts for up to one season in advance. They are couched in probabilistic terms and are very general.

\section{Data and forecasts}

Some meteorologists have made specific forecasts for years in advance. In a paper delivered in 1972 at the Annual Meeting of the American Geophysical Union, Krick (1972) stated that

the computer output permits the preparation of daily prognostic charts for years into the future of sufficient quality to be used effectively in the evaluation of the weather factor in relation to any human activity [and that] no deterioration in the quality of the forecasts occurs during the prediction interval, whether it be a few days or several years.

To illustrate the procedure and the accuracy of the forecasting system, a 6-day series of daily prognostic sea-level pressure charts was given. They covered the period 17-22 January 1977 and are shown in Fig. 1. Note that these 5-year prognostics contain considerable detail: exact locations of highs, lows, fronts, troughs, and ridges.

The statement of the AMS (1976) used the term "weather" to mean such elements as rain, wind, and

0003-0007/78/1598-1602\$05.00

(C) 1979 American Meteorological Society temperature rather than pressure fields and fronts. It is, however, common practice for meteorologists to use prognostic charts to help predict weather, and the above excerpt from Krick (1972) ties prognostic pressure charts to weather forecasts.

The actual weather charts for the verifying period 17-22 January 1977 are shown in Fig. 2. The problem is to determine how good the 5-year prognostics arehow much skill is demonstrated. It was decided to use both subjective and objective methods to make this determination.

\section{Verification}

In the subjective test a group of four experienced Los Angeles forecasters was asked to compare the 5-year prognostic charts with the verifying charts and to rate them as excellent, good, fair, poor, or very poor. In making the comparisons, the forecasters were asked to evaluate the 5-year prognostic charts as they would evaluate the routine $30 \mathrm{~h}$ prognostic charts issued by the National Meteorological Center. They were not told either the origin of the charts or how far in advance they had been prepared. Specifically, they were asked to compare locations of highs, lows, fronts, and pressure gradients. It was assumed that the isobaric interval on the 5-year charts was $5 \mathrm{mb}$ and that the verifying time was 1200 GMT. The results of the subjective evaluation are shown in the first column of Table 1.

On the basis of the prognostic chart for 20 January, the forecast was made (Krick, 1972) 5 years in advance that "The Presidential Inaugural of January 20, 1977,

TABLE 1. Subjective evaluation of the 5-year prognostics by a group of forecasters (first column) and correlations between verifying sea-level pressures and: 5-year prognostics (second column), January sea-level normal pressures (third column), 5-day prognostics (fourth column), and $30 \mathrm{~h}$ prognostics (fifth column).

\begin{tabular}{cccccc}
\hline \hline $\begin{array}{c}\text { Jan. } \\
1977\end{array}$ & $\begin{array}{c}\text { Sub- } \\
\text { jective }\end{array}$ & 5 Years & Normal & 5 Days & $\begin{array}{c}30 \\
\text { Hours }\end{array}$ \\
\hline 17 & Poor & 0.07 & 0.55 & 0.46 & 0.95 \\
18 & Fair & 0.59 & 0.33 & 0.16 & 0.90 \\
19 & Poor & 0.23 & 0.38 & 0.42 & 0.93 \\
20 & Poor & 0.68 & 0.49 & 0.12 & 0.85 \\
21 & Poor & 0.29 & 0.47 & -0.39 & 0.82 \\
22 & Poor & -0.04 & 0.20 & 0.37 & 0.88 \\
Average & & 0.30 & 0.40 & 0.19 & 0.89 \\
\hline
\end{tabular}




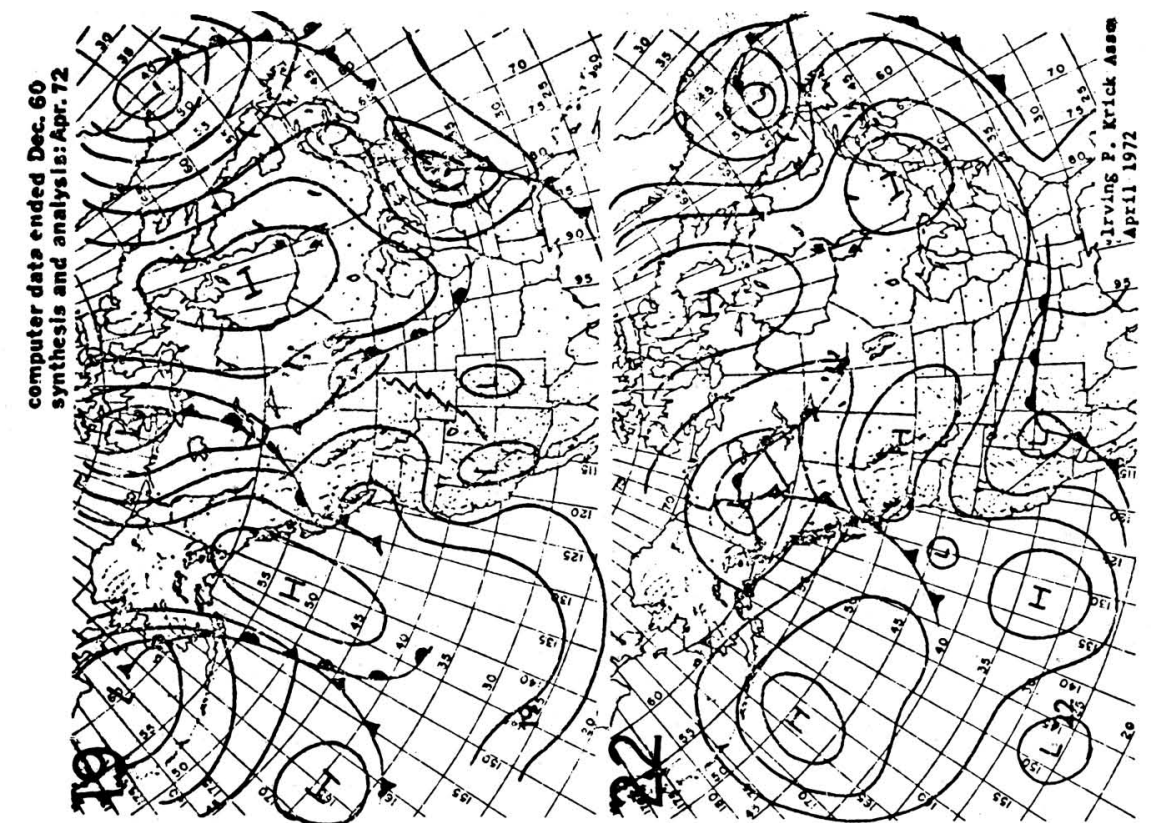

是

至

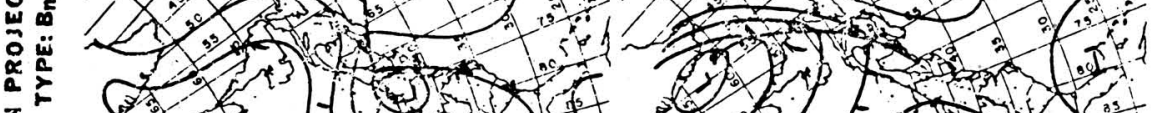

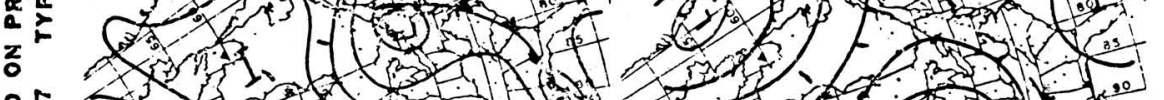

要

के

(4)

年

告

75

(1)

...

(1)

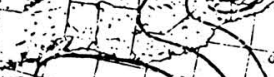

s a a d a

3.


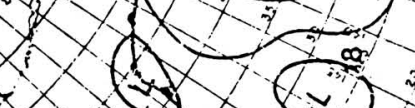

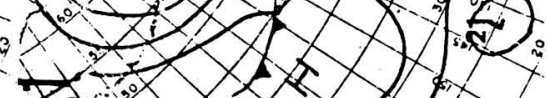

से

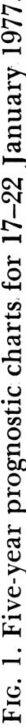
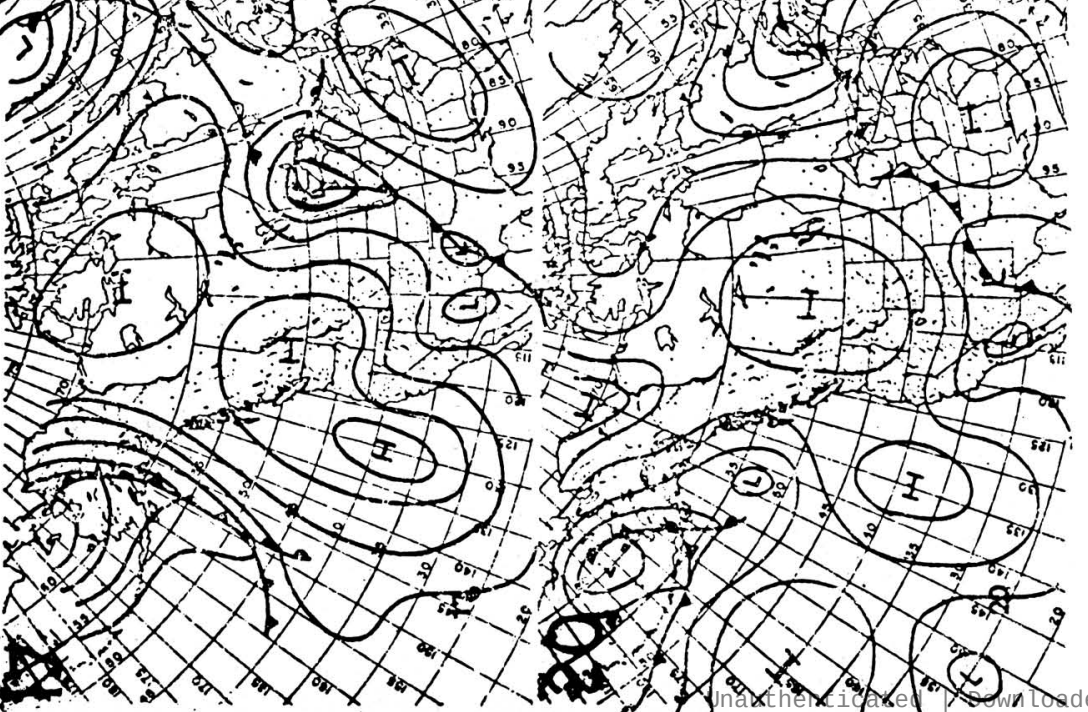

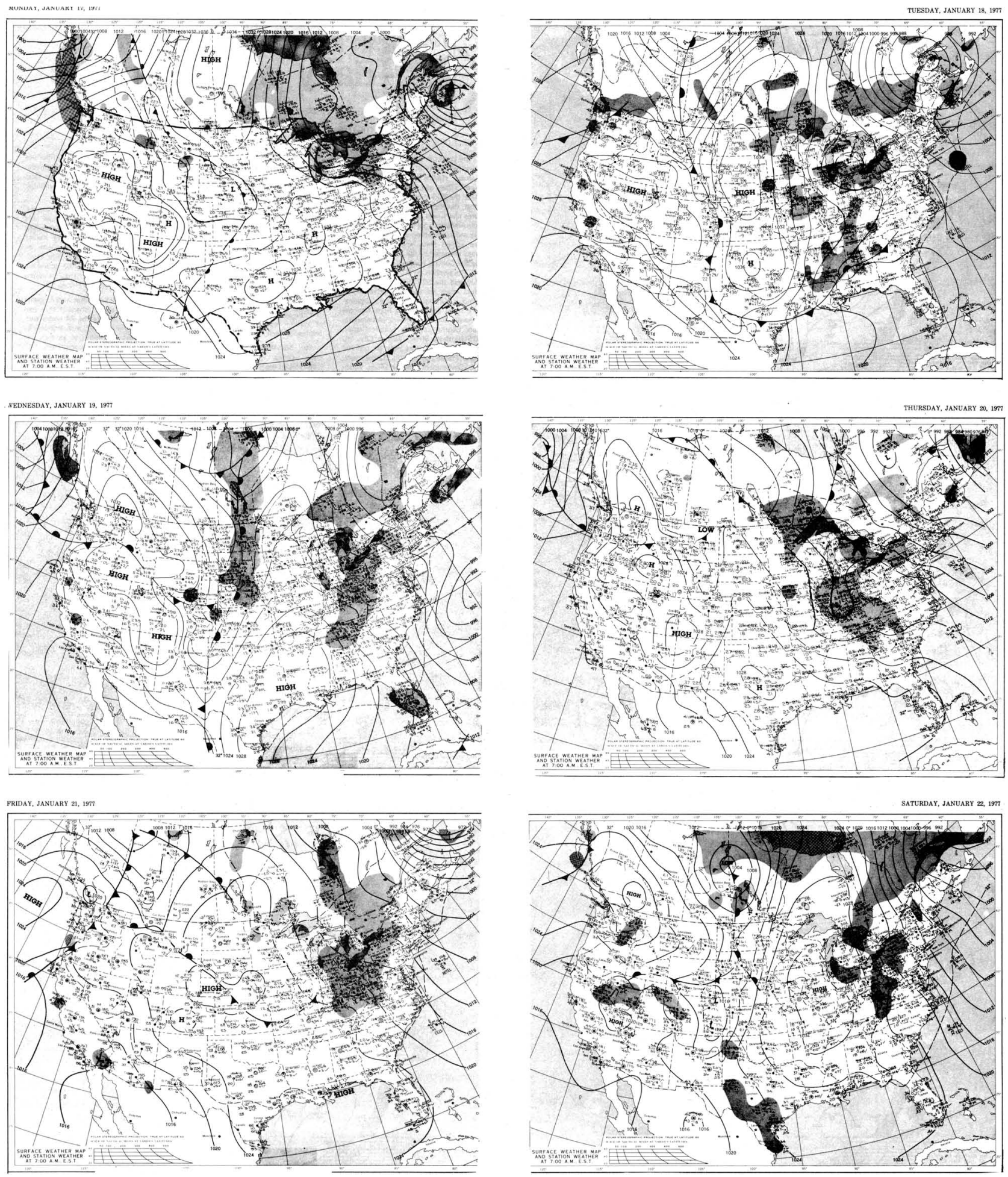

FIG. 2. Weather maps 1200 GMT 17-22 January 1977.

should occur on a cool, fair day in Washington, D.C. ..." Those who were in Washington on that day or watched the President, on television, walk up Pennsylvania Avenue will surely agree that the forecast was brilliantly verified. One should keep in mind, however, that the January climatological record shows that a clear or partly cloudy day occurs $48 \%$ of the time in Washington, D.C., and the normal midday temperatures are in the $40 \mathrm{~s}\left({ }^{\circ} \mathrm{F}\right)$.

The objective evaluation consisted of computing four correlation coefficients for each day. These were the correlation coefficients between sea-level pressures observed and 1) the 5-year prognostic, 2) the January nor- 
mal, 3) the 5-day prognostic, and 4) the $30 \mathrm{~h}$ prognostic.

Pressures were read at a grid of $\mathbf{5} 4$ points covering the contiguous United States and adjacent areas. The points were at $5^{\circ}$. latitude/longitude intersections extending from $50^{\circ} \mathrm{N}$ to $30^{\circ} \mathrm{N}$ and from $130^{\circ} \mathrm{W}$ to $70^{\circ} \mathrm{W}$.

Figure 3 shows the 5-day prognostic charts, and Fig. 4 shows the $30 \mathrm{~h}$ prognostic charts verifying at 1200 GMT for the period 17-22 January 1977.

The second column of Table 1 shows the correlation between the verifying observations and the 5-year prog- nostic chart. Interestingly enough the best correlation is on Inaugural Day. Further, the 5-year coefficients for 18 and 20 January are higher than any of the coefficients computed by using the normal for the forecasts (third column of the table). The normal, however, had a better average score for 6 days.

When the 5-day prognostic charts were compared with the verifying charts, the prognostics yielded the coeffcients shown in fourth column of the table. The range of coefficients was greater for the 5-day prognostics than

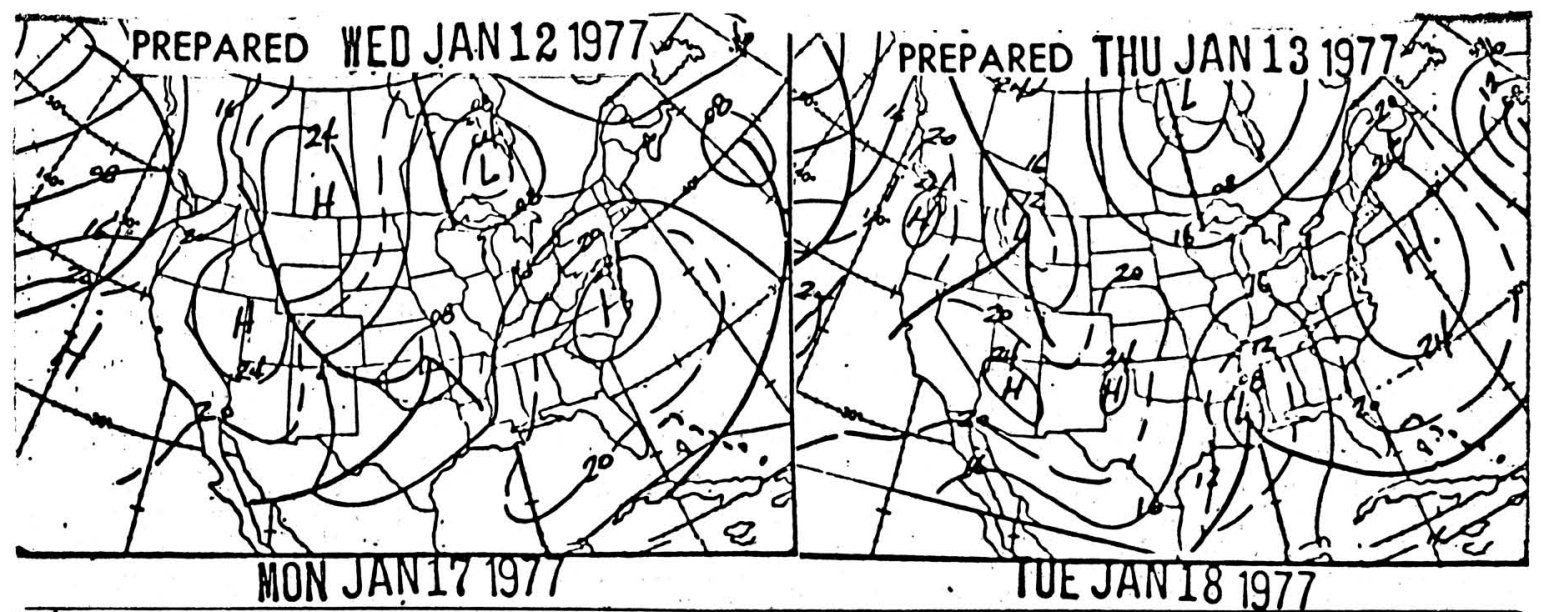

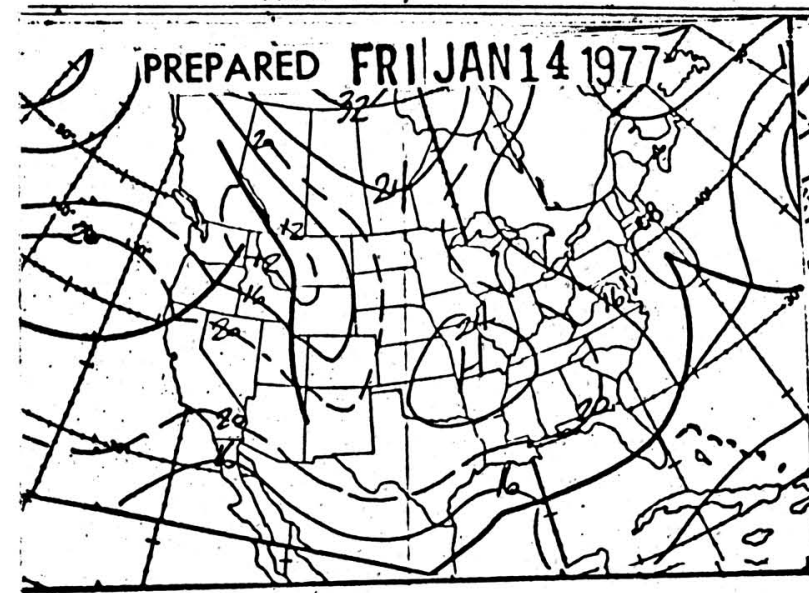

HED JAN19 1977

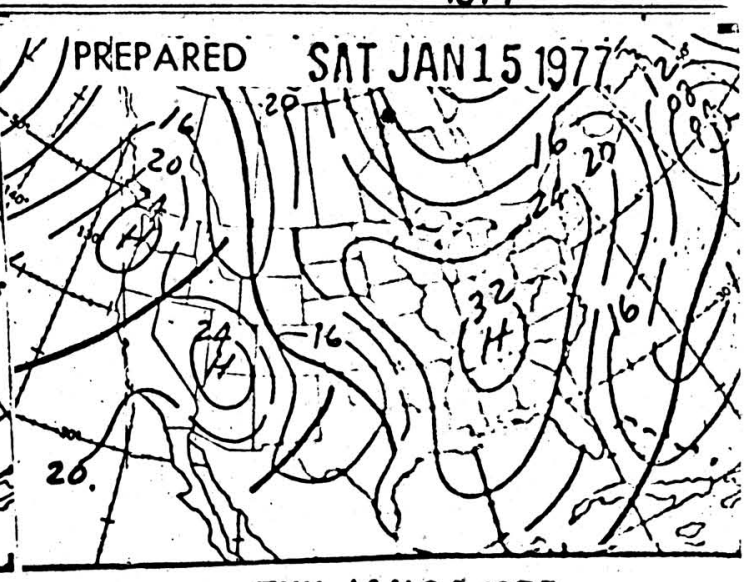

THU JAN 201977

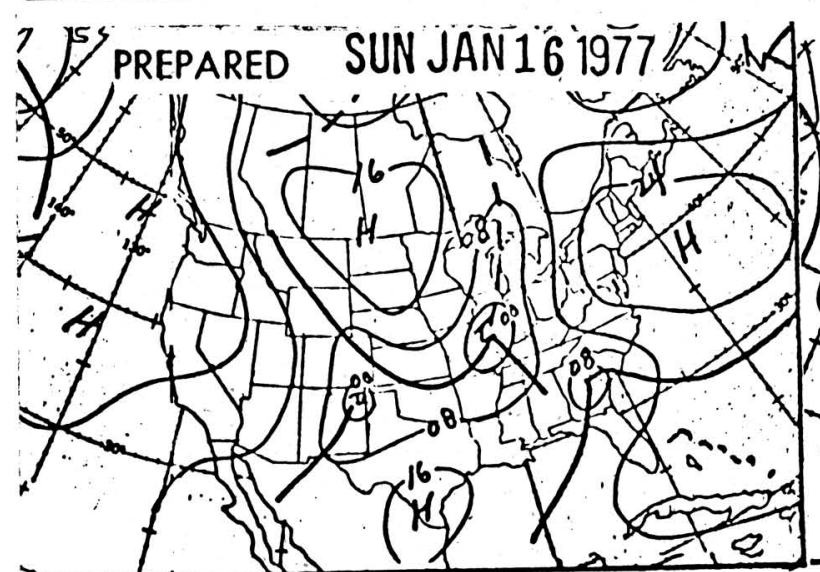

FRI JAN 211977

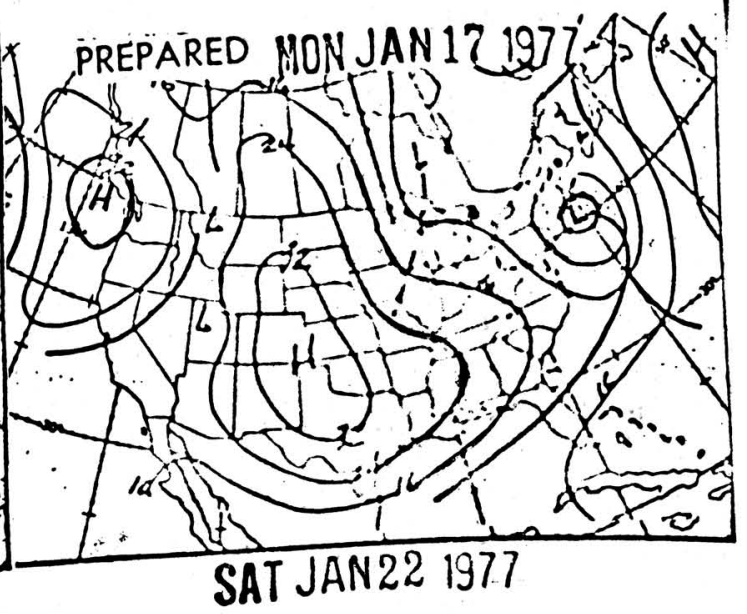

FIG. 3. Five-day prognostic charts for 1200 GMT 17-22 January 1977. 

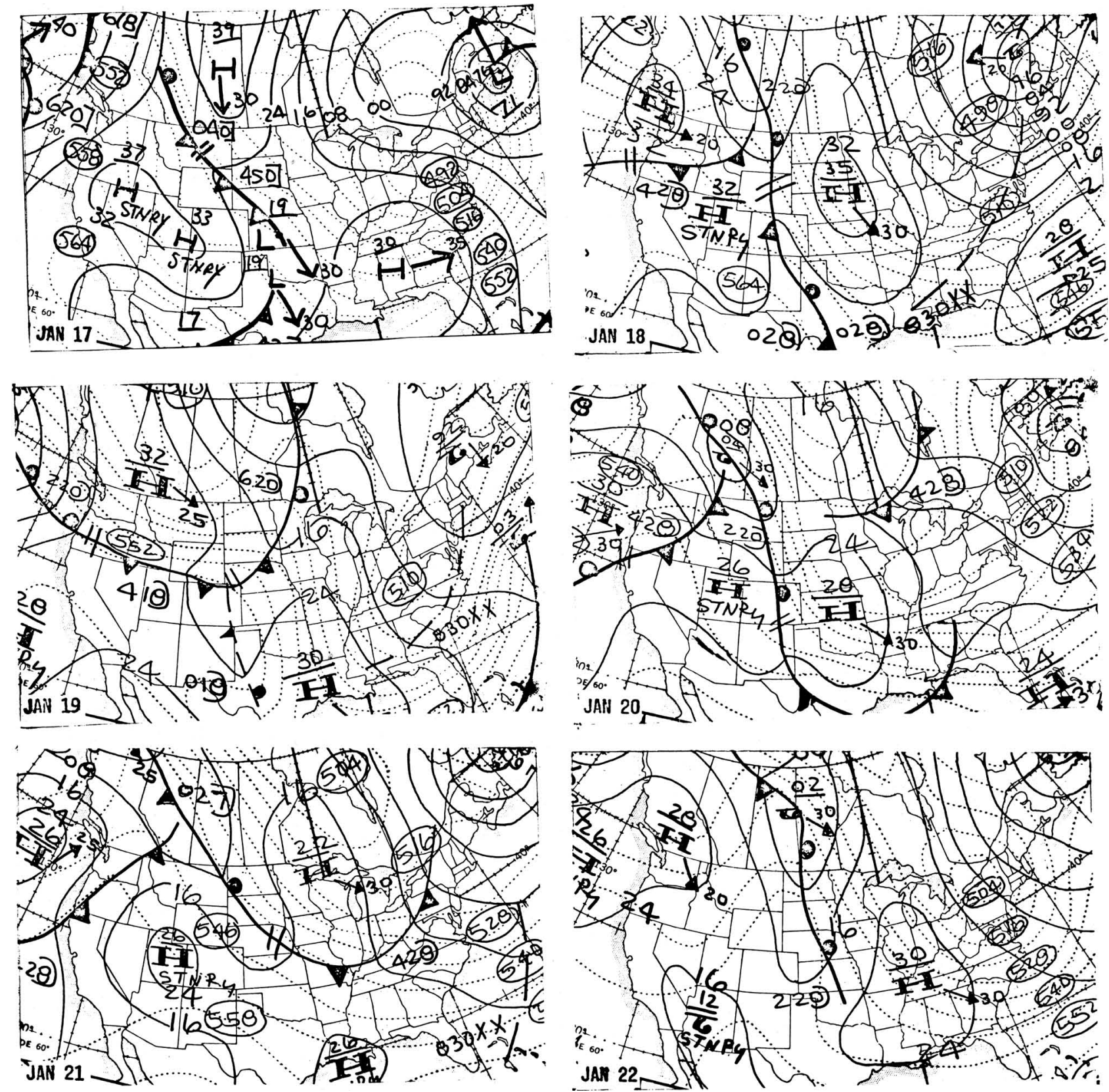

FIG. 4. Thirty-hour prognostic charts for 1200 GMT 17-22 January 1977.

it was for the 5-year prognostics. The 5-year average score was the better.

The last column clearly shows that the 5-year prognostics are completely outclassed by the $30 \mathrm{~h}$ prognostics. But one could reasonably argue that it is hardly fair to compare a 5-year forecast with a $30 \mathrm{~h}$ forecast for an exact time. Perhaps a lag of a day or so should be considered. However, an examination of the data did not suggest that a lag of plus or minus a day or two would improve the scores much.

\section{Conclusion}

The data at hand are, of course, insufficient to draw solid conclusions about the quality of forecasts made years in advance. However, if one uses the test recommended by the AMS (1976, p. 1460)-“Unless forecast accuracy exceeds levels achieved by basic methods such as these [climatology], skill cannot be said to exist"-then the 5-year forecasts for 17-22 January 1977 demonstrated no skill and neither did the 5-day forecasts.

\section{References}

AMS, 1976: Policy statement of the American Meteorological Society on Weather Forecasting. Bull. Am. Meteorol. Soc., 57, 1460-1461.

Krick, I. P., 1972: A viable method of ultra long range weather prediction. Paper presented at the 53rd Annual meeting of the American Geophysical Union, Washington, D.C. 